\title{
A lecturer profile categorization for evaluating education practice quality
}

\author{
David Lopez \\ Barcelona Science and Engineering Education Research Group \\ Universitat Polotècnica de Catalunya - BarcelonaTech \\ Barcelona, Spain \\ david@ac.upc.edu
}

\begin{abstract}
This research-to-practice work in progress paper is focused on creating a categorization of lecturers in order to define quality in their education practice. The reason for this work is that we found that our faculty perceived the time devoted to teaching as something that had no real impact on the progress of their academic careers, whereas the real impact consists of papers published and grants obtained. Our lecturers require from the university an institutional policy that defines strategies and guidelines to favour a quality education, which in turn requires the definition of a teaching evaluation system. However, a single evaluation system cannot be implemented for all teachers. Different teaching profiles must be defined and the lecturers must be evaluated in accordance with the profiles to which they belong. In this paper, a categorization of four lecturer profiles is presented.
\end{abstract}

Keywords-Faculty development, Educational institutions, Career development

\section{Motivation}

The Universitat Politècnica de Catalunya (UPC) is a technical university that only offers degrees in engineering, sciences and architecture. We have conducted a research project which concerns changing the attitude of lecturers to the teaching-learning process. Basically, the idea behind the project is that the opinions of lecturers about their own teaching depend on the students they have taught, the subject they teach, their previous experience and the beliefs that guide their work $[1,2,3]$. As part of the project, we began a study by posing the following research question: "Why is the involvement of our lecturers in teaching so low?" To this end, a series of interviews and focus groups were conducted with our lecturers. While the objective of this paper is not to show the results of this study, we arrived at some conclusions that led us to consider a further approach. One of the conclusions was that our lecturers thought their colleagues did not consider educational innovation as relevant. When asked why, they responded that their peers did not usually give importance to the educational part of university life, because only published papers and grants obtained were taken into account for recruitment and promotion. The time devoted to the improvement of education was thus regarded as a "waste of time", and was frowned upon because lecturers did not spend their time on activities that raised the prestige or improved the finances of the department, but rather on matters of lesser importance. According to the interviewees, part of the solution to this situation was an increase in resources educational innovation, and recognition for those individuals who excelled in a high-quality teaching. However, their chief demand was for the university to come forward with an institutional policy that defined strategies and established guidelines for fostering a quality education in which innovation was key.

These results throw light on a fresh problem and a different question: Does our current institutional policy help lecturers to invest their time and effort in providing high-quality teaching, or does it in fact do more to impede it?

\section{Quality EVALUATION}

In Spain, most of the universities are public, so lecturers are public servants and therefore their salary is regulated by the government. Salaries depend on category, seniority and the quality evaluations obtained.

The national evaluation is divided into two sections, one based on the evaluation of research and the other on teaching. These evaluation processes are voluntary; meeting the requirements of these processes leads to a salary increase, and in the case of research evaluation, advantages when applying for funding for projects. Quality research evaluation is mainly based on papers published. On the other hand, the national teaching evaluation process is based on four inputs: 1) the teaching hours taught; 2) the evaluation of the lecturer by the departments and schools to which the lecturer belongs; 3 ) the satisfaction surveys completed by the students, and 4) a report containing a critical assessment of the teaching provided by lecturers themselves. According to the data provided in the annual report issued by the association of universities in our country, only $64.56 \%$ of the lecturers obtain a positive evaluation of their research quality. However, the figures exceed $95 \%$ where the quality of teaching evaluation is concerned. Nevertheless, promotion is based on having a positive research evaluation, not on the teaching evaluation.

In light of this information, we can affirm that the belief of our lecturers that teaching activities are not as important for their professional careers as research activities is indeed an inconvenient truth. The we focused on developing a methodology for evaluating education practice which motivate lecturers to be involved in a better education practice. 


\section{RELATED WORK}

For many years, the university has prioritized the scientific training of professors and research capacity over the ability to train good professionals. This inertia derives from the centuryold primacy of research over teaching, despite research showing that there is no association between excellence as a researcher and as a teacher. Shulman [4] changed this perception of the relationship between a good researcher and a good teacher by recognizing that effective teaching requires the transformation of knowledge into something accessible and understandable to learners at their respective levels of development. This change in perception is gaining ground in some fields [5], for example, in the field of medicine [6]. Where the engineering environment is concerned, engineering education research is emerging as a field of inquiry [7], with movements like the Scholarship of Teaching and Learning [8]. But the development of high-quality education requires recognition for those who practise it: according to the study by Kinchin et al [9], "For Engineering, the tensions are clear, with a suggested need for concerted consolidation of personal and institutional drivers, as well as a genuine appreciation of diversity in the work place ".

The strategies of change with potential relevance for STEM degrees has been studied by Henderson, Beach and Finkelstein [10] where they define four categories of change strategies: 1) Curriculum and pedagogy; 2) Reflective teachers; 3) Policy; and 4) Shared vision. From the analysis conducted at our university, we conclude that strategy 3 , policy, is the least developed. Institutional support is necessary, since according to Winstone and Millward [11], if the experimentation undertaken by a teacher is perceived as too risky, lecturers only innovate as a result of some personal motivation rather than in the expectation of institutional approval or reward.

Borrego and Henderson [12] propose two examples of strategies for the policy: quality assurance and organizational development. The authors affirm, quoting [13], "The STEM undergraduate system will be changed by requiring institutions (...) to collect evidence demonstrating their success in undergraduate education. What gets measured is what got improved". Likewise, they state that: "The STEM undergraduate system will be changed by administrators with strong vision who can develop structures and motivate faculty to adopt improved instructional practices".

In order to develop our proposal, we have studied three successful models of teacher quality assessment, those of the Netherlands, the United Kingdom and Australia.

\section{A. The Dutch model}

Prior to 2008, the only requirements to qualify as a professor in Dutch universities were based on research. In 2008 all Dutch research universities signed the Mutual Agreement of University Teaching Qualification (UTQ). The UTQ is currently mandatory by consensus among the universities rather than by law. A deep description of this model can be found in the article by de Jong et al [14], an analysis of the results obtained in the article by Oude Alink et al [15], and in the report from the Association of Universities of the Netherlands (VSNU) [16].
This model offers its teachers didactic courses, and the evaluation is based on a portfolio and there are two types of accreditation: the BKO (Base Kwalificatie Onderwijs University Teaching Qualification) and the SKO (Senior Kwalificatie Onderwijs - Senior Teaching Qualification). It is mandatory to have the BKO to teach full- or part-time. Should the BKO not be available in the first contract, teachers are unable to acquire a permanent contract or promotion until they are accredited. In order to be accredited, teachers are required to create a portfolio containing evidence of their teaching activity. This portfolio includes: evaluation by the students; evaluation by a supervisor; a self-reflection report on the development of one's teaching, and recommendations of peers acting as mentors. The portfolio is assessed by an evaluation committee that decides whether the evidence is sufficient to receive accreditation or if the teacher needs to complete some training courses offered by the university.

Once the BKO has been obtained, teachers can decide to extend their teacher training and obtain the SKO, which in addition to their teaching responsibilities implies a leadership role in the development of education in their schools or departments. Teachers draw up a special portfolio containing innovative initiatives that is added to the evidence of the BKO.

The system is highly regarded by teaching staff, as it offers opportunities to "apply and experience different strategies, to reflect on possible teaching mistakes and possible points to improve, understanding the reasons behind them" [15].

\section{B. The Australian model}

The University Teaching \& Criteria \& Standards model (http://uniteachingcriteria.edu.au) is funded by the Australian Office of Learning and Teaching (OLT) and is a joint initiative by five Australian universities. The project was designed to respond to significant changes in the higher education sector due to the growth in demand for higher education, the increase in global competition, the broadening of student demographics and the availability of new technologies. A description of the model can be found in Chalmers et al [17], and Probert [18].

One explicit objective was to identify, support and reward quality education. The framework is intended as a practical, flexible guide to assist universities and their academic staff in clarifying what constitutes quality teaching. The framework is underpinned by carefully researched definitions and principles of quality teaching that are expressed through seven criteria: 1) Design and planning of learning activities; 2) Teaching and supporting student learning; 3) Assessment and giving feedback to students on their learning; 4) Developing effective learning environments, student support and guidance; 5) Integration of scholarship, research and professional activities with teaching and in support of student learning; 6) Evaluation of practice and continuing professional development; and 7) Professional and personal effectiveness

The academic career is divided into five levels, each one more demanding than the previous: Lecturer A, Lecturer B, Senior Lecturer, Associate Professor, and Professor. For each of these categories a clear definition is given of what should be done in each of the seven criteria and how to obtain evidences. Each university develops its own protocol for reaching the 
desired standards through the indicators proposed by the model. There is no accreditation at the national level or a common commission among universities.

\section{The United Kingdom model}

In the UK, higher education institutions are autonomous, each one being responsible for the quality of its own programs and the degrees it offers. The national assessment is carried out by the Quality Assurance Agency using the UK Quality Code for Higher Education, which is focused on developing mechanisms to enhance professionalism in teaching. One of the most highly regarded quality systems is that launched in 2011 by the UK Higher Education Academy and known as the Professional Standards Framework (UKPSF) for teaching and supporting learning in higher education [19].

The UKPSF is a guide to recognizing roles in teaching and leadership in higher education, with the idea that the professional development programs of each university should provide evidence that they have met all the standards. It is articulated in three inter-related dimensions of practice (Activity, Knowledge and Values) whose purpose is to reflect the complexity of the professional role of staff teaching and supporting learning. The dimensions are subdivided into 5 areas of Activity undertaken by teachers and supporters of learning within higher education; 6 aspects of core Knowledge that are needed to carry out those activities at the appropriate level; and 4 professional Values that someone performing these activities should embrace and exemplify [20,21].

The UKPSF differentiates four teacher positions throughout the academic career: Associate Fellow, Fellow, Senior Fellow, and Principal Fellow. Each of these positions has defined objectives to be achieved in each of the three dimensions.

\section{OUR PROPOSAL}

The system proposed herein is not based on levels to be reached, but rather on profiles where the professors find themselves at a specific moment in their academic careers, and among which they can change practically from any profile to another. The profiles are fourfold: 1) Basic teaching, for new lecturers or lecturers who have other main assignments from the university, such as management positions or those in charge of projects with companies; 2) Advanced teaching, where lecturers know the didactics of their areas of knowledge and apply innovative methodologies; 3) Leadership in teaching, where the lecturer manages and designs subjects, groups of subjects or degrees, as well as generating innovative material and promoting teaching innovation; and 4) Researchers in education in their field of knowledge, with their teaching and research deeply interconnected.

The way to reach some profiles is through accreditation with the realization of courses for lecturers, and experimentation with the help of more experienced peers, to develop a teaching portfolio based on evidence that the university could assess and therefore prove that the conditions for the change are met. Although a lecturer can be accredited to belong to one of the profiles, it is not mandatory to belong to it.
Lecturers lodge a request with the university for which profile they wish to belong, bearing in mind that their teaching will be evaluated according to this profile. A teaching quality commission will decide if lecturers' requests are accepted.

The point of entry into the academic career would be Basic Teaching. Moving from Basic Teaching to Advanced Teaching would be carried out by means of an accreditation similar to that of the models studied in the previous section. Once a lecturer has been accredited the Advanced Teaching level, he or she would not lose this accreditation. In the same way, the move from the Advanced Teaching profile to Leadership in Teaching would be carried out by means of an accreditation that, once obtained, would not be lost. The move to Researcher in Education would be voluntary and would not require accreditation, although only lecturers with Leadership in Teaching accreditation could request this change. The university would be the body that accepts (or even promotes) changes to this profile, based on its global educational strategy and its teaching staff. Lecturers with a Researcher in Education profile could request a change to the Leadership in Teaching profile, if for any reason their main research topic ceases to be the education in their area of knowledge. Lecturers can move from any profile to the Basic Teaching profile at any time during their academic careers because the university makes an assignment for a specific task, such as being a department director or vice-chancellor, or if a lecturer has the opportunity to lead an important research or company project. In this case, and due to the demanding nature of this specific task, a lecturer can request a change to the Basic Teaching profile and be evaluated according to the parameters of this profile. When the lecturer has completed the specific task, he or she can request the university for a return to his or her previous profile.

\section{A. Profile 1: Basic Teaching}

Definition: Lecturers at this level are either new or have a high-demanding task assigned by the university. They have some duties as lecturers, but their main task at this time in their careers is different (and may change in the future).

Activities: an effective and decent teaching activity; a good relationship with students and colleagues; performing tasks assigned by their head of studies or coordinators and assist students with their doubts. Moreover, should this lecturer be new, he or she should undertake the necessary activities to be accredited for the next level in a period between one and five years. Activities that are not expected of these persons are: preparation of lecture notes; transparencies; design of subjects or curricula, or leadership in the application of innovative teaching techniques. A lecturer belonging to this profile should never be alone in a subject, neither should all teachers of the same subject have this profile.

Courses and activities to be undertaken: a lecturer with this profile should participate in workshops on the use of resources in class (voice, non-verbal communication, etc.); organization of a class; teamwork, and alignment of teaching objectives with exam questions. Also, the training should include courses on teacher organization, innovative methods, design of training activities and teacher competencies. 
Quality evaluation should be based on the teaching hours taught; the evaluation of the lecturer by the departments and schools to which the lecturer belongs, and on the satisfaction surveys completed by students. In fact, these three factors should be evaluated in all the four profiles. In addition, novice teachers should be evaluated in order to determine if they are following the appropriate steps to be accredited for the next profile in the time required.

\section{B. Profile 2: Advanced Teaching}

Definition: lecturers with a few years of experience who are engaged in teaching, although they may have other tasks. They should know the didactics of their respective areas of knowledge as well as some innovative methodologies, and be involved in improving student motivation and learning.

Activities: those of the previous profile, although they may also be asked to be the coordinator of the subject, write lecture notes, develop videos, design laboratory activities and so on, justifying the innovative methods used in each case.

Courses and activities: these teachers must take courses in subject design; curriculum coordination and design; advanced teaching methodologies and evaluation. They should also propose improvements in their subjects and disseminate their experience in education congresses, basically in the category of innovative practice, which would constitute evidence that would allow them to be accredited for the next level.

Quality evaluation: the quality committee should evaluate the involvement of these lecturers in subject coordination; teaching material developed; workshops in which they have participated; teaching innovations carried out and publication of these innovations in congresses and education magazines.

\section{Profile 3: Leadership in Teaching}

Definition: lecturers in this profile are committed to advancing educational methods and should focus on how to achieve deep student learning. They must be able to design new processes, thereby seeking true learning experiences.

Activities: these lecturers may be asked to be a degree or specialty coordinator, head of studies or someone in charge of a degree, thereby contributing to an improvement in the teaching quality with their work. Likewise, they may be asked to design courses for the training of other lecturers. They should participate regularly in forums of educational innovation. They should publish regularly in congresses and education magazines, in the categories of innovative practice and research to practice. The only thing they cannot be asked to do is to make education their main research topic

Activities that should be carried out: workshops on teaching quality, evaluation, innovative methods etcetera. These courses do not necessarily form part of the university lecturer training program, but rather of the workshops that normally accompany congresses in education.

Quality evaluation: the quality committee should evaluate lecturer involvement in accordance with the workshops they have attended; the articles published; the teaching innovation projects carried out; the courses they have designed, both for students and for the lecturer training program; the teaching material developed and the management positions held.

\section{Profile 4: Researchers in Education}

The task of lecturers in this profile is to assume leadership regarding education issues in their environment, which requires a deep knowledge of educational theories and their application in the discipline. They must have a deep knowledge of the studies they teach as well as the profession itself. They should also be acquainted with successful experiences of innovative educational methods in the environment of engineering and science. Their teaching and research should be deeply interconnected, most of their publications being in congresses and journals devoted to these topics, as well as conducting high-quality research. They should lead national and international education research projects in their respective disciplines and be in contact with other research groups engaged in a similar subject. In this profile, the quality committee should evaluate lecturer involvement in research projects in education (especially those which have obtained funding); leadership in the improvement of their department, degree or university; articles published and the quality of the congress or magazine where they have been published.

\section{DISCUSSION AND FUTURE WORK}

This is a theoretical model and a work in progress. More research work is required to refine the model. Also, if our university decides to adopt it, we will analyze the difficulties of its implementation as well as study if it has a significant impact on the vision and engagement of our lecturers in education.

The professional careers of university lecturers should not consist of superhuman workloads entailing a permanent combination of quality teaching and research, leadership of basic research projects with applications to industrial projects, as well as the responsibilities of an administrative position. This is simply an impossible demand, as pointed out by Richard Felder in "The Myth of Superhuman Professor" [22]. Lecturers are able to change their main tasks throughout their professional lives. No one is under the obligation to change his or her profile: it is perfectly acceptable to be accredited for Advanced Teaching without wishing to be accredited for Leadership in Teaching. Nevertheless, it would be interesting if, in order to obtain a Tenured Position, the university required the applicant to be accredited for Advanced Teaching, or in order to hold a Professorial Chair, accreditation for Leadership in Teaching. Furthermore, our proposal includes a profile of Researcher in Education, something that is not contemplated in other models.

Teachers belonging to the four profiles should be present in a University or a Department. A group of professors who work in a department or a degree course should be defined as a team; that is, a balanced group in which it should be clear to everyone that they succeed or fail as a team and not as individuals. The fact that all the lecturers can request to belong to one of the profiles, and that the university and each department are fully aware of the profiles of its faculty, can help in the design of the recruitment and promotion policy of the teaching staff. 


\section{REFERENCES}

[1] Kagan, Dona M. "Implication of research on teacher belief." Educational psychologist 27, no. 1 (1992): 65-90.

[2] Prawat, Richard S. "Teachers' beliefs about teaching and learning: A constructivist perspective." American journal of education 100, no. 3 (1992): 354-395.

[3] Posner, George J., Kenneth A. Strike, Peter W. Hewson, and William A. Gertzog. "Accommodation of a scientific conception: Toward a theory of conceptual change." Science education 66, no. 2 (1982): 211-227.

[4] Shulman, Lee S. "Those who understand: Knowledge growth in teaching." Educational researcher 15, no. 2 (1986): 4-14.

[5] Fink, L. Dee, Susan Ambrose, and Daniel Wheeler. "Becoming a professional engineering educator: A new role for a new era." Journal of Engineering Education 94, no. 1 (2005): 185-194.

[6] Irby, David M., and Patricia S. O'sullivan. "Developing and rewarding teachers as educators and scholars: remarkable progress and daunting challenges." Medical education 52, no. 1 (2018): 58-67.

[7] Borrego, Maura, and Jonte Bernhard. "The emergence of engineering education research as an internationally connected field of inquiry." Journal of Engineering Education 100, no. 1 (2011): 14-47.

[8] Fanghanel, Joëlle, Jane Pritchard, Jacqueline Potter, and Gina Wisker. "Defining and supporting the Scholarship of Teaching and Learning (SoTL): a sector-wide study.(Literature review)." (2016). Higher Education Academia Report. Retreived online 20 of March, 2019 at: https://repository.uwl.ac.uk/id/eprint/2066/1/literature_review.pdf.

[9] Kinchin, I. M., E. Alpay, Katherine Curtis, J. Franklin, C. Rivers, and N. E. Winstone. "Charting the elements of pedagogic frailty." Educational Research 58, no. 1 (2016): 1-23.

[10] Henderson, Charles, Andrea Beach, and Noah Finkelstein. "Facilitating change in undergraduate STEM instructional practices: An analytic review of the literature." Journal of research in science teaching 48, no. 8 (2011): 952-984.

[11] Winstone, Naomi, and Lynne Millward. "Reframing perceptions of the lecture from challenges to opportunities: Embedding active learning and formative assessment into the teaching of large classes." Psychology Teaching Review 18, no. 2 (2012): 31-41.

[12] Borrego, Maura, and Charles Henderson. "Increasing the use of evidence-based teaching in STEM higher education: A comparison of eight change strategies." Journal of Engineering Education 103, no. 2 (2014): 220-252.
[13] Steering Committee for Evaluating Instructional Scholarship in Engineering. "Developing Metrics for Assessing Engineer Instruction: What Gets Measured is What Gets Improved". Washington, DC: National Academy of Engineering. 2009.

[14] de Jong, Riekje, Jaap Mulder, Paul Deneer, and Hanno van Keulen. "Poldering a teaching qualification system in Higher Education in the Netherlands: a typical Dutch phenomenon." REDU: Revista de Docencia Universitaria 11, no. 3 (2013): 23.

[15] Oude Alink, Charlotte, Alberto Martinetti, Armağan Karahanoğlu, and Marije Hahnen-Florijn. "Non-Natural Born lecturers: How to survive teaching in Dutch higher education." In 4th International Conference on Higher Education Advances (HEAD'18), pp. 1205-1213. Editorial Universitat Politècnica de València, 2018.

[16] De Groot, Johanna, and Rianne Kouwenaar. "Professionalisation of university lecturers. The UTQ and beyond". VSNU Report, May 2018. Last consult March 21, 2019. Available on line at http://www.vsnu.nl/ files/documenten/Professionalisation $\% 20 \mathrm{of} \% 20$ university $\% 201$ ecturers. pdf

[17] Chalmers, Denise, Rick Cummings, Sofia Elliott, Sue Stoney, Beatrice Tucker, Rachel Wicking, and Trina Jorre de St Jorre. "Australian university teaching criteria and standards project." (2014). On line: http://dro.deakin.edu.au/eserv/DU:30105033/jorredestjorreaustralianuniversity-2014.pdf

[18] Probert, Belinda. The quality of Australia's higher education system: how it might be defined, improved and assured. Australian Government Office for Learning and Teaching, 2015. On line: https://tr.edu.au/resources/Probert_Quality_Aust_HE_2015.pdf

[19] Thornton, Tim. "Professional recognition: promoting recognition through the Higher Education Academy in a UK higher education institution." Tertiary Education and Management 20, no. 3 (2014): 225238.

[20] Ayres, Ruth L. "Impact assessment in higher education: a strategic view from the UK." Information and Learning Science 119, no. 1/2 (2018): 94-100.

[21] Smith, Holly, Frances Deepwell, and Liz Shrives. "Measuring the impact of the UK professional standards framework for teaching and supporting learning (UKPSF)." (2013). On line: https://www.heacademy.ac.uk/sites/default/files/resources/ukpsf_impact study_report.pdf

[22] Felder, Richard M. "The myth of the superhuman professor." Journal of Engineering Education 83, no. 2 (1994): 105-110. 